ISSN 0103-5150

Fisioter. Mov., Curitiba, v. 30, n. 3, p. 433-441, Jul./Sep. 2017

Licenciado sob uma Licença Creative Commons

DOI: http://dx.doi.org/10.1590/1980-5918.030.003.A001

\title{
Analysis of pain, functional capacity, muscular strength and balance in young women with Patellofemoral Pain Syndrome
}

\author{
Análise da dor, funcionalidade, comportamento muscular e equilíbrio \\ em mulheres jovens com Síndrome da Dor Femoropatelar
}

\author{
Camile Ludovico Zamboti ${ }^{[a]}$, Rubens Alexandre da Silva Junior ${ }^{[b]}$, Cynthia Gobbi ${ }^{[a]}$, \\ Leonardo Shigaki $^{[a]}$, Christiane de Souza Guerino Macedo ${ }^{[a] *}$
}

[a] Universidade Estadual de Londrina (UEL), Londrina, PR, Brazil

[b] Universidade Norte do Paraná (UNOPAR), Londrina, PR, Brazil

\section{Abstract}

Introduction: Patellofemoral Pain Syndrome (PFPS) is associated with anterior knee pain, changes in functional capacity, balance and muscle strength disorders. Objective: To quantify pain, functional capacity, strength in quadriceps (Q), gluteus medium (GM), hip external rotator (ER) muscles and balance in sedentary women with PFPS. Methods: Twenty sedentary women, aged 18 to 25 years, were divided into two groups: PFPS $(\mathrm{N}=10)$ and control group $(\mathrm{N}=10)$. All the volunteers answered the items of the Visual Analogue Scale (VAS), the Lysholm Knee Score Scale, the Anterior Knee Pain Scale (AKPS), and the Lower Extremity Functional Scale (LEFS). The participants performed the following tests: maximal voluntary isometric contraction measured by dynamometry; postural balance using the Star Excursion Balance Test (SEBT) and a force platform. Statistical analyses were performed using the Shapiro Wilk test, the Mann Whitney U test and Spearman's correlation coefficient. Data were submitted to SPSS 20 software. Results: The PFPS group presented greater pain, balance impairment and higher average velocity of oscillation; however, no differences were observed in Q, GM and RE muscle strength and in balance analyzed by SEBT. Conclusion: Women with PFPS exhibited

*CLZ: undergrad, e-mail:camileludovico@hotmail.com

RASJ: PhD, e-mail: rubensalex@hotmail.com

CG: MS, e-mail: cynthiagobbi@hotmail.com

LS: MS, e-mail: leonardoshigaki@hotmail.com

CSGM: PhD, e-mail: chmacedo@yahoo.com.br

Fisioter Mov. 2017 Jul/Sep;30(3):433-441 
greater pain, worse functional capacity and body balance. Moderate correlation between both balance tests suggests the use of SEBT when the force platform is not available, which could facilitate and highlight the importance of clinical diagnosis with regard to postural balance.

Keywords: Patellofemoral Pain Syndrome. Knee. Physical Therapy Specialty.

\section{Resumo}

Introdução: A Síndrome da Dor Femoropatelar (SDFP) está relacionada à dor anterior do joelho, alteração de funcionalidade, déficits de equilíbrio e força muscular. Objetivo: Quantificar a dor, funcionalidade, força muscular do quadríceps (Q), glúteo médio (GM), rotadores externos de quadril (RE) e o equilíbrio em mulheres com SDFP. Métodos: Avaliou-se 20 voluntárias, sedentárias, entre 18 e 25 anos; divididas em grupo SDFP (N=10) e controle $(N=10)$. Todas responderam a Escala Visual Analógica de Dor, Lysholm Knee Score Scale, Anterior Knee Pain Scale e Lower Extremity Functional Scale, realizaram a contração isométrica voluntária máxima dos músculos $Q$, GM e RE por meio de dinamometria e análise do equilíbrio postural pelo Star Excursion Balance Test (SEBT) e plataforma de força. Para análise estatística utilizou-se os testes Shapiro Wilk, Mann Whitney e Correlação de Spearmann, pelo SPSS ${ }^{2}$ 20. Resultados: O grupo SDFP apresentou maior dor, incapacidade e velocidade média de oscilação do centro de pressão, entretanto não foram observadas diferenças para a força muscular de Q, GM e RE e equilíbrio analisado pelo SEBT. Estabeleceu-se correlação moderada entre SEBT e Centro de Oscilação de Pressão (COP) unipodal. Conclusão: Mulheres com SDFP apresentam maior dor, pior funcionalidade e alterações no equilíbrio corporal. A correlação moderada entre SEBT e o COP-unipodal aponta a possibilidade de uso deste teste funcional quando a plataforma de força não é acessível, o que facilita e destaca a importância do diagnóstico clínico do equilíbrio postural.

Palavras-chave: Síndrome da Dor Patelofemoral. Joelho. Fisioterapia.

\section{Introduction}

Patellofemoral pain syndrome (PFPS) is described as retropatellar or anterior knee aching pain and characterized by crepitation in the patellofemoral joint during and after activities, such as squatting, walking up or down stairs and sitting for prolonged periods (1). Sedentary women are more likely to develop PFPS (2). It affects 1 in 4 individuals, with 20 to $40 \%$ of the population with ages between 15 and 35 years (3). Some anatomical variations, namely pelvic width, femoral antevesion, quadriceps angle, tibial torsion, quadriceps strength and knee joint laxity, are seen more commonly in women (4). Factors believed to contribute to production of patellar pain include poor alignment between the joint surfaces, muscle shortening, weak vastus medialis oblique (VMO), different recruitment patterns between VMO and vastus lateralis (VL), weak quadriceps muscles, vigorous training and incongruity between patella and femoral trochlear groove (5 - 8).
The quadriceps muscle is responsible for activating the forces exerted on the patella, whose function is to control the position of the patella in relation to the trochlea (9). Improper positioning of the patella, differences in quadriceps muscle recruitment and pain can affect balance and motor control in PFPS (10). The VMO opposes the lateral vector force of the VL. The imbalance between these muscles may contribute to the emergence of symptoms as it changes the biomechanics of the knee and increases the patellofemoral compression forces. Another factor related to PFPS is the weakness of the GM and the ER muscles $(11,12)$. Fukuda et al. (13) determined that the strengthening of these muscles may reduce pain and improve functional capacity.

It is known that body balance is essential for daily life activities and sports (14). With regards to PFPS, Citaker et al. (15) found that women with PFPS had worse postural balance during the balance test on an unstable platform. Chen et al. (16) also observed that individuals with chronic knee instability presented worse score during the Star Excursion Balance Test (SEBT). 
Considering the high prevalence of women with PFPS that seek for physical therapy, the biomechanical changes previously reported in the literature, the disagreement between results established by research on PFPS, and the possibility of using SEBT as a functional test for the analysis of balance in this population, it is believed that studies are still needed to establish and determine the biomechanical standards for assessment and rehabilitation.

Therefore, the main purpose of this study was to quantify pain, functional capacity, and quadriceps (Q), gluteus medium (GM), hip external rotator (ER) muscle strength and balance in sedentary women with PFPS.

\section{Methods}

- Ethical aspects

This was a cross-sectional study approved by the Research Ethics Committee of the institution (Case N. 251637/2013).

- Sample

The sample size calculation was performed using the Power and Sample Size software (Vanderbilt School of Medicine Biostatistics, Nashville, TN), with $95 \%$ confidence interval, $5 \%$ level of significance and $80 \%$ power, considering the mean and standard deviation of the parameter data obtained before SEBT (16). The volunteers were 20 sedentary, university female students divided into two groups: the PFPS group $(n=10)$ and the control group $(n=10)$.

The inclusion criteria for the PFPS group, according to Santos et al. (5), were: presence of at least three clinical signs, such as patellar crepitus, high patella, contracture of the iliotibial band, retraction iliotibial tract, excessive subtalar pronation, patellar hypo or hypermobility, patellar malalignment and lateral tibial torsion; report of three or more functional conditions including squatting, going up and down the stairs, kneeling, running, sitting for a long period of time; pain intensity of 3 or more in the VAS. The volunteers in the control group should not present any pain intensity in the knee joint or anywhere else in the last six months, but the presence of up to two signs of postural changes was accepted. The exclusion criteria for both groups were: recent history of knee surgery; cardiovascular, neurological or rheumatological diseases; diabetes or alteration of plantar sensitivity; use of medication; previous physical therapy; and inability to perform the functional tests proposed in this study or to attend the scheduled assessments.

- Procedures

The flowchart of the experimental procedures is presented in Figure 1. On the first day of data collection, all the participants filled out a form with name, age, height and weight and marked the items on the VAS-pain $(17,18)$, the Anterior Knee Pain Scale AKPS) (19), Lysholm Knee Score Scale (20) and the Lower Extremity Functional Scale (LEFS) $(21,22)$. The volunteers were informed about the objectives of the study and agreed to participate by providing their free and informed consent.

Prior to performing all measurements, the subjects were familiarized with the maximum voluntary isometric contraction (CIVM), followed by the measurement of Q, GM and ER muscle strength using a dynamometer (EMG System do Brasil ${ }^{\circledR}$ Ltda, São José dos Campos - SP, Brazil).

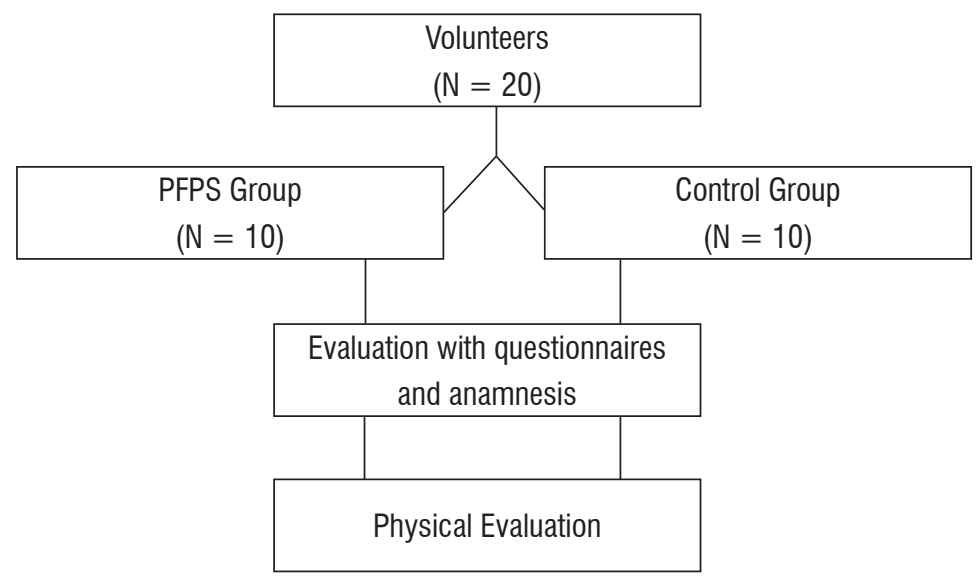

Figure $\mathbf{1}$ - Flow chart for sample selection and data collection. 
For the measurement of quadriceps strength, the volunteer sat on a chair with the back supported and fixed, knee in open kinetic chain in $60^{\circ}$ flexion for greater muscle activation of VL and VMO muscles (23). An ankle strap connected to a force transducer was fastened to the volunteer, who was verbally encouraged to strengthen while extending the knee and maintain it during 10 seconds of MVIC (Figure 2A).

For the MVIC of the hip lateral rotators, the chair was positioned laterally to the force transducer (Figure 2B). For the GM muscle, the volunteer remained in decubitus contralaterally to the member to be tested, while performing MVIC abduction at $30^{\circ}$ (Figure 2C). All tests were carried out following a sequence protocol for data collection: quadriceps, external rotators and gluteus medium. The mean of the three values found was considered for the analysis.

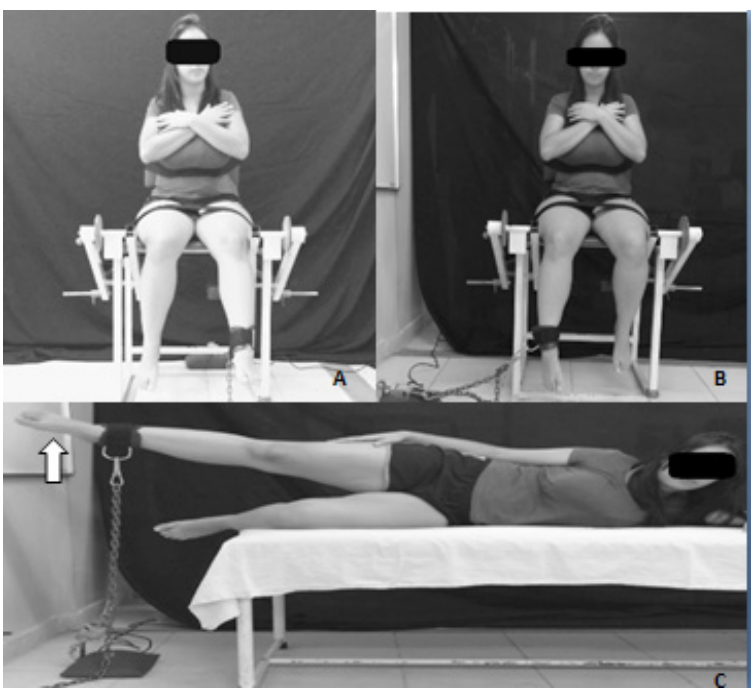

Figure 2A - Analysis of quadriceps muscle strength. B Analysis of hip external rotator muscle strength. C - Analysis of gluteus medium muscle strength.

On the first collection day, the SEBT was used to measure balance $(24,25)$. For this test, the volunteer performed three repetitions, with 30 -second intervals between each one. In the PFPS group, the lower limb with pain was analyzed. In the control group, the lower limb to be analyzed was chosen by the volunteer. After completing the test, the reach distance in each direction was normalized to the lower-limb length of each volunteer to obtain the percentage of the three directions, as shown in the formula below (24), where A indicates the anterior distance, PM the posteromedial distance, PL the posterolateral distance, LL the length of the lower limb and the result is the percentage of the three directions.

$$
\frac{(\text { Anterior + Posteromedial + Posterolateral })}{3 \text { X Limb Length }} \times 100
$$

Finally, after a week of the initial assessment, balance was tested on a force platform (BIOMEC400EMG System do Brasil ${ }^{\circledR}$ Ltda, São José dos Campos -SP, Brazil). The participants stood with eyes open, under unipodal condition performed with the limb with pain (in PFPS group) and leg preferred for 30s. There was a rest period of approximately 30 s between each trial. The procedure was repeated three times and the mean was retained for analysis (26). The parameters associated with movements of the center of pressure (COP) were: the ellipse area (95\%) of the COP (A-COP in $\mathrm{cm} 2$ ) and mean velocity (VEL in $\mathrm{cm} / \mathrm{s}$ ) of the COP sway in the mediolateral (M/L) direction.

- Statistical Analysis

Normal data distribution was verified using the Shapiro-Wilk test. Student's $t$-test was used for between-group comparisons for each variable. The Spearman's correlation coefficient was used to examine the relationship between the balance data. The statistical analysis was performed using SPSS version 20 for Windows (SPSS Inc.; Chicago, IL, USA), with a $5 \%$ level of significance $(p<0.05)$.

\section{Results}

The groups were homogeneous regarding height, weight and body mass index (BMI). Both groups presented mean values and standard deviation, respectively: age $21.1 \mathrm{~m}(1.10)$ and 22.0 (1.59) ( $\mathrm{p}=0.019)$; height $1.65(0.06)$ and $1.64(0.03)(\mathrm{p}=0.379)$; weight 60.2 (8.07) and 63.0 (7.40) ( $\mathrm{p}=0.739)$; and BMI 21.8 (1.79) and 23.25 (3.20) ( $\mathrm{p}=0.721)$. Mean and standard deviation of pain in the PFPS group were 3.75 years and 1.24 years, respectively. In the CG, it was zero. The results obtained through the questionnaires and functional scales showed that the PFPS group had increased pain and disability, with significant differences compared to the control group (Table 1).

No significant difference was observed between the groups regarding the quadriceps, hip external rotator and gluteus medium muscle strength and balance analyzed using SEBT (Table 2). The analysis 
of postural balance measures obtained using a force platform showed significant differences between the groups for the mean velocity of the COP sway in the mediolateral direction, with better balance control in the CG (Table 2). The correlation was considered moderate for COP-unipodal and SEBT $(\mathrm{p}=0.046, \mathrm{r}$ $=0.451)$ (Table 3$)$.

Table 1 - Results of questionnaires and functional scales for the PFPS and Control groups using the Mann Whitney U test

\begin{tabular}{lccc}
\hline & $\begin{array}{c}\text { PFPS } \\
\mathbf{N}=\mathbf{1 0}\end{array}$ & $\begin{array}{c}\text { CONTROL } \\
\mathbf{N}=\mathbf{1 0} \\
\text { Median (min/max) }\end{array}$ & Median (min/max) \\
\hline VAS & $4(3-7)$ & 0 & $\mathbf{p}$ \\
AKPS & $80(48-98)$ & $100(94-100)$ & 0.014 \\
Lysholm & $89(47-100)$ & $100(95-100)$ & 0.000 \\
LEFS & $75.5(53-98)$ & $79.5(78-80)$ & 0.000 \\
\hline
\end{tabular}

Note: PFPS- Patellofemoral Pain Syndrome; VAS- Visual Analogue Scale; AKPS- Anterior Knee Pain Syndrome; LEFS- Lower Extremity Functional Scale.

Table 2 - Analysis of muscle strength and balance between women with PFPS and control group using the Mann Whitney U test

\begin{tabular}{lccc} 
& PFPS & CONTROL & \\
Muscles & $\mathbf{N}=\mathbf{1 0}$ & $\mathbf{N}=\mathbf{1 0}$ & P \\
Median (min/max) & Median (min/max) & \\
\hline Gluteus medium (kgf) & $4.74(3-7)$ & $5.48(2-7)$ & 0.241 \\
Quadriceps (kgf) & $24.63(14-34)$ & $24.34(20-38)$ & 0.427 \\
External rotators (kgf) & $8.7(5-11)$ & $8.65(6-10)$ & 0.449 \\
SEBT-Anterior & $82.5(71-86)$ & $81.25(70-87)$ & 1.0 \\
SEBT-Posteromedial & $71(48-79)$ & $72.5(62-83)$ & 0.353 \\
SEBT- Posterolateral & $77.7(56-87)$ & $81.5(68-87)$ & 0.218 \\
SEBT- General & $89.53(68-95)$ & $92.74(80-98)$ & 0.393 \\
COP Unipodal (cm2) & $8(2-13)$ & $6.17(4-8)$ & 0.143 \\
MV mediolateral Unipodal (cm/s) & $2.85(1-4)$ & $0.64(1-3)$ & 0.000
\end{tabular}

Note: PFPS- Patellofemoral Pain Syndrome; SEBT-Star Excursion Balance Test; kgf - Kilogram-force; COP- Center of Oscillation of Pressure; MV- Mean Velocity.

Table 3 - Spearman's correlation coefficients between SEBT, mean unipodal velocity and COP unipodal for the PFPS group

\begin{tabular}{lccc}
\hline Instruments & SEBT & MV UNIPODAL & COP UNIPODAL \\
\hline SEBT & $1.000(p=0.000)$ & $0.383(p=0.093)$ & $0.451(p=0.046)$ \\
MV UNIPODAL & $0.383(p=0.093)$ & $1.000(p=0.000)$ & $0.614(p=0.004)$ \\
COP UNIPODAL & $0.451(p=0.046)$ & $0.614(p=0.004)$ & $1.000(p=0.000)$ \\
\hline
\end{tabular}

Note: PFPS- Patellofemoral Pain Syndrome; SEBT- Star Excursion Balance Test; COP- Center of Oscillation of Pressure; MV- Mean Velocity. 


\section{Discussion}

The present study showed that sedentary women with patellofemoral pain syndrome exhibited greater pain, functional impairment and velocity of the COP sway in the mediolateral direction. Patellofemoral pain is multifactorial and is therefore difficult to examine and treat.

This study proved that pain and balance impairment are important aspects to be considered in the rehabilitation of this dysfunction. Pain is the main symptom of PFPS and can be subjectively evaluated using VAS which also appears to be a valid and reliable instrument (17). The results of the present study showed that women with PFPS revealed a significantly greater improvement in the intensity of pain. This result agrees with Souza et al. (27) that have also observed an increase in the intensity of pain in individuals with PFPS compared to controls. Piazza et al. (4) added that there was exacerbation of pain during activities, such as squatting, going up or down stairs or ramp, and walking on flat surface.

With pain increase in daily life activities, the functional capacity should be considered. The use of questionnaires and the AKPS, Lysholm and LEFS scales has established significantly lower values for the PFPS group. The AKPS was validated and translated into Brazilian Portuguese for measuring PFPS (19). It can also predict pain and functional limitations of the individuals. Bolgla et al. (12) and Fukuda et al. (28) showed that subjects with PFPS yielded a score between 64.5 and 80 in AKPS, which corroborate the score of 80 points obtained in the current study for this group. The LEFS can be used to evaluate the functional impairment of a patient with a disorder of one or both lower extremities. The results showed lower values, indicating worse functional capacity in the lower limb of women with PFPS.

With regard to functional capacity, the results obtained using the Lysholm Knee Scale questionnaire also showed lower values for the PFPS group, as well as the results obtained by Dickschas et al. (29), who found similar scores to those found for individuals with chronic patellar instability.

The study has also assessed the strength of the hip abductor and external rotator muscles in women with PFPS. This assessment can be justified by the association of the weakness of these muscles with that of the knee valgus, as well as the association between the dynamic valgus and the unipodal support during functional activities and sports. It is believed that the knee valgus position gives support to the patellar lateral region with the external condyle of femur leading to chondral lesion and causing pain (28). Bolgla et al. (12) hypothesized that women with PFPS would demonstrate significantly less hip abductor and hip external rotator strength when compared to controls. A similar result was found by Meira et al. (30) with regard to hip strength muscles.

Other authors claimed that there is less hip strength as well as greater impairment in quadriceps muscle strength (31). However, no significant differences were found in quadriceps muscle strength in the study carried out by Souza et al. (26) and in our study. Barton et al. (8) reported that the recruitment of the GM muscle occurs significantly late during functional activities, therefore, the dysfunction could appear in muscle activation and not in muscle strength. These results may have been influenced by the sample that included young volunteers with normal daily activities, with complaints of pain, and also by a sample that obtained a maximum score of 80 (AKPS), as established by Fukuda et al. (28).

The present study investigated static postural control using the SEBT (16). It is a lower extremity functional test that can be easily applied in the clinical and research settings by physical therapists when a force platform, the gold standard for the analysis of body balance, is not available. The SEBT has been shown to be a reliable measure and has validity as a dynamic test to predict risk of lower extremity injury, to identify dynamic balance deficits in patients with a variety of lower extremity conditions (32). Chen at al. (16) observed that individuals with chronic ankle instability had significantly smaller reaching distance in the posterior-lateral and posterior-medial during SEBT. This finding differed from that of our study, which did not show any significant differences, even in the normalization of all directions. The results obtained have established a moderate correlation between the SEBT and COP-unipodal provided by the force platform; this means that the SEBT can be considered useful for the analysis of balance, mainly in clinical practice.

While using the force platform, Citaker et al. (15) observed that the static unipodal standing balance in the PFPS group was significantly worse, similar to our study in which the PFPS group showed higher mean velocity of oscillation in unipodal standing, however, 
the difference for the ellipse area of the COP was not significant.

Our findings are in agreement with data reported by Lee et al. (33), who compared postural stability between women with PFP and pain-free controls in unipodal standing on a force platform and showed worse performance and higher mean velocity of oscillation in the PFPS group. The literature demonstrates that in great lower limb impairment or imbalance caused by neuromuscular deficits, the main muscle groups used in mediallateral performance are the hip adductors and abductors returning to symmetrical stance in centre of gravity (34). In addition, Gribble and Hertel (35) found worse performance in the PFPS group, with significant difference regarding the ellipse area of the COP after testing sessions of isokinetic fatigue of the hip abductors. In contrast, our study did not observe significant differences in COP and in GM muscle strength.

The present study focused on the results for the characterization of functional capacity and pain in individuals with PFPS, as well as of balance impairment compared to the control group, which should be considered in further investigations. The use of the SEBT in our study is worth mentioning, considering that it is a functional and inexpensive postural control measurement tool that does not require high technology, which determines the usefulness of SEBT in the management of PFPS. As a significant contribution to clinical practice, it is suggested that evaluation and rehabilitation techniques that create balanced lower body strength in women with PFPS should be conducted. In addition, clinical tests for PFPS assessment such as AKPS, Lysholm, LEFS and SEBT should be used to reestablish the functional capacity of these patients.

However, it must be taken into consideration that the results from the present study are not consistent with those reported in recent literature probably because of the small sample size and the high degree of functional capacity observed in the PFPS group, which comprised young women with a mean score of 4 on the VAS for pain.

\section{Conclusion}

The results obtained showed no significant differences in the SEBT and in the ellipse area of the COP for the gluteus medium, quadriceps and hip external rotator muscle strength and balance. However, women with PFPS exhibited greater pain, worse functional capacity and body balance provided by the AKPS, Lysholm and LEFS, also greater balance impairment, higher mean velocity of oscillation in single-leg stance. Moreover, the SEBT proved to be a useful clinical parameter as it established a moderate correlation with the COP-unipodal to evaluate the dynamic balance of women with PFPS. However, further investigations should be carried out with inclusion criteria to establish higher scores for pain and lower for functional capacity.

\section{References}

1. Bevilaqua-Grossi D, Felício LR, Silvério GWP. Início da atividade elétrica dos músculos estabilizadores da patela em indivíduos com SDPF. Acta Ortop Bras. 2009;17(5):297-9.

2. Bevilaqua-Grossi D, Felício LR, Simões R, Coqueiro KRR, Monteiro-Pedro V. Avaliação eletromiográfica dos músculos da patela durante exercício isométrico de agachamento em indivíduos com síndrome da dor femoropatelar. Rev Bras Med Esporte. 2005;11(3):159-63.

3. Levinger P, Gilleard W. The heel strike transient during walking in subjects with patellofemoral pain syndrome. Phys Ther Sport. 2005;6(2):83-8.

4. Piazza L, Lisboa ACA, Costa V, Brinhosa GCS, Vidmar MF, Oliveira LFB, et al. Sintomas e limitações funcionais de pacientes com síndrome da dor patelofemoral. Rev Dor. 2012;13(1):50-4.

5. Santos GM, Say KG, Pulzato F, Oliveira AS, BevillaquaGrossi D, Pedro VM. Relação eletromiográfica integrada dos músculos vasto medial oblíquo e vasto lateral longo na marcha em sujeitos com e sem síndrome de dor femoropatelar. Rev Bras Med Esporte. 2007;13(1):17-21.

6. Ribeiro ACS, Bevilaqua-Grossi D, Foerster B, Candolo C, Pedro VM. Avaliação eletromiográfica e ressonância magnética do joelho de indivíduos com síndrome da dor femoropatelar. Rev Bras Fisioter. 2010;14(3):221-8. 
7. Garcia FR, Azevedo FA, Alves N, Carvalho AC, Padovani CR, Negrão Filho RF. Efeitos da eletroestimulação do músculo vasto medial oblíquo em portadores de síndrome da dor patelofemoral: uma análise eletromiográfica. Rev Bras Fisioter. 2010;14(6):477-82.

8. Barton CA, Lack S, Maliaras P, Morrisey D. Gluteal muscle activity and patellofemoral pain syndrome: a systematic review. Br J Sports Med. 2013;47(4):207-14.

9. Nobre TL. Comparação dos exercícios em cadeia cinética aberta e cadeia cinética fechada na reabilitação da disfunção femoropatelar. Fisioter Mov. 2011;24(1):167-72.

10. Saad MC, Felício LR, Masullo CL, Liporaci RF, Bevilaqua-Grossi D. Analysis of the center of pressure displacement, ground reaction force and muscular activity during step exercises. J Electromyogr Kinesiol. 2011;21(5):712-8.

11. Souza RB, Powers CM. Differences in hip kinematics, muscle strength, and muscle activation between subjects with and without patellofemoral pain. J Orthop Sports Phys Ther. 2009;39(1):12-9.

12. Bolgla LA, Malone TR, Umberger BR, Uhl TL. Hip strength and hip and knee kinematics during stair descent in females with and without patellofemoral pain syndrome. J Orthop Sports Phys Ther. 2008;38(1):12-8.

13. Fukuda TY, Rosseto FM, Silva RM, Apolinário A. Fortalecimento dos músculos do quadril no tratamento da dor anterior do joelho. Ciência\&Saúde. 2009; especial:96.

14. Duarte M, Freitas SMSF. Revisão sobre posturografia baseada em plataforma de força para avaliação do equilíbrio. Rev Bras Fisioter. 2010;14(3):183-92.

15. Citaker S, Kaya D, Yuksel I, Yosmaoglu B, Nyland J, Atay $\mathrm{OA}$, et al. Static balance in patients with patellofemoral pain syndrome. Sports Health. 2011;3(6):524-7.

16. Chen CY, Hsu AT, Guo LY, Lin CF, Chen YA. Postural control and lower extremity contribution during star excursion balance test in athletes with chronic ankle instability. Formosan Journal of Physical Therapy. 2011;36(4):263-73.

17. Thommé R, Augustsson J, Karlsson J. Patellofemoral Pain Syndrome: A review of current issues. Sports Med. 1999;28(4):245-62.
18. Price DD, McGrath PA, Rafii A. The validation of visual analogue scales as ratio scale measures for chronic and experimental pain. Pain. 1983;17(1):45-56.

19. Aquino VS, Falcon SFM, Neves LMT, Rodrigues CR, Sendin FA. Tradução e adaptação cultural para a língua portuguesa do questionário scoring of patellofemoral disorders: estudo preliminar. Acta Ortop Bras. 2011;19(5):273-9.

20. Peccin MS, Ciconelli R, Cohen, M. Questionário específico para sintomas do joelho "Lysholm knee scoring scale" - tradução e validação para a língua portuguesa. Acta Ortop Bras. 2006;14(5):268-72.

21. Binkley JM, Stratford PW, Riddle DL. The lower extremity functional scale (LEFS): scale development, measurement properties, and clinical application. North American Orthopaedic Rehabilitation Research Network. Phys Ther. 1999;79(4):371-83.

22. Pereira LM, Dias M, Mazuquin BF, Castanhas LG, Menacho MO, Cardoso JR. Translation, cross-cultural adaptation and analysis of the psycometric properties of the lower extremity functional scale (LEFS): LEFS- BRAZIL. Bras J Phys Ther. 2013;17(3):272-80.

23. Javadpour SM, Finegan PL, O’ Brien M. The anatomy of the extensor mechanism and its clinical relevance. Clin J Sport Med. 1991;1(4):229-35.

24. Filipa A, Byrnes R, Paterno MV, Myer GD, Hewett TE. Neuromuscular training improves performance on the Star Excursion Balance Test in young female athletes. J Orthop Sports Phys Ther. 2010;40(9):551-8.

25. Hertel J, Braham RA, Hale SA, Olmsted-Kramer LC. Simplifying the Star Excursion Balance Test: Analyses of Subjects with and without Chronic Ankle Instability. J Orthop Sports Phys Ther. 2006;36(3):131-7.

26. Rabello LM, Macedo CSG, Oliveira MR, Fregueto JH, Camargo MZ, Lopes LD, et al. Relação entre testes funcionais e plataforma de força nas medidas de equilíbrio em atletas. Rev Bras Med Esporte. 2014;20(3):219-22.

27. Souza AC. Síndrome da dor femoropatelar - Análise eletromiográfica, isocinética, ressonância magnética, dor e fadiga [dissertation]. São Carlos (Brazil): Universidade Federal de São Carlos; 2005. Portuguese. 
28. Fukuda TY, Magalhaes E, Sacramento SR, Forgas A, Cohen M, Abdalla RJ. A comparison of hip strength between sedentary females with or without patellofemoral pain syndrome. J Orthop Sports Phys Ther. 2010;40(10):641-7.

29. Dickschas J, Harrer J, Pefefferkorn R, Strecker W. Operative treatment of patellofemoral maltracking with torsional osteotomy. Arch Orthop Trauma Surg. 2012;132(3):289-98.

30. Meira EP, Brumitt J. Influence of the Hip on patients with patellofemoral pain syndrome: a systematic review. Sports Health. 2011;3(5):455-65.

31. Waryasz GR, McDermott AY. Patellofemoral pain syndrome: a systematic review of anatomy and potential risk factors. Dyn Med. 2008;7:9.

32. Gribble PA, Hertel J. Using the Star Excursion Balance Test to assess dynamic postural-control deficits and outcomes in lower extremity injury: a literature and systematic review. J Athl Train. 2012;47(3):339-57.
33. Lee SP, Souza RB, Powers CM. The influence of hip abductor muscle performance on dynamic postural stability in females with patellofemoral pain. Gait Posture. 2012;36(3):425-9.

34. Shigaki L, Rabello LM, Camargo MZ, Santos VBC, Gil AWO, Oliveira MR, et al. Análise comparativa do equilíbrio bipodal em atletas de ginástica rítmica. Rev Bras Med Esporte. 2013;19(2):104-7.

35. Gribble PA, Hertel J. Effect of hip and ankle muscle fatigue on unipedal postural control. J Electromyogr Kinesiol. 2004;14(6)641-6.

Received in 09/11/2015

Recebido em 11/09/2015

Approved in 08/11/2016

Aprovado em 11/08/2016 
